\title{
Senyawa Toksik Pencemar Udara: Polycyclic Aromatic Hydrocarbons (PAHs)
}

\author{
NIA YUNIARTI HASAN ${ }^{1}$ \\ 1. Jurusan Kesehatan Lingkungan Politeknik Kesehatan Kemenkes Bandung \\ Email:niayhasan@gmail.com
}

\begin{abstract}
ABSTRAK
Polycyclic Aromatic Hydrocarbons (PAHs) merupakan kelompok senyawa bersifat karsinogenik atau mutagenik, terutama benzo[a]pyrene. PAHs tersebar melalui proses dispersi atmosfer, sehingga dapat ditemukan di daerah yang jauh dari sumbernya. Sumber PAHs antara lain emisi batu bara, produksi aluminium, pemanas rumah, kegiatan memasak, kendaraan bermotor, kebakaran hutan, pembangkit listrik batubara dan pembakaran sampah. Deposisi kering, deposisi basah dan penguapan dari air serta tanah merupakan proses pertukaran PAHs udara, air, udara dan tanah. Paparan PAHs pada manusia terjadi melalui pernafasan, mulut dan penyerapan kulit.PAHs pada partikel-partikel udara kurang dari $10 \mu m$ (PM10) dapat terhirup dan selanjutnya terakumulasi pada sistem pernapasan manusia, sehinggamenyebabkan gangguan kesehatan manusia.Baku mutu udara ambien senyawa toksik PAHs perlu ditetapkan untuk melindungi kesehatan masyarakat.
\end{abstract}

Kata kunci: benzo[a]pyrene, karsinogenik, deposisi

\begin{abstract}
Polycyclic Aromatic Hydrocarbons (PAHs) are a group of carcinogenic or mutagenic compounds, especially benzo[a]pyrene. PAHs are dispersed by atmospheric processes and found in the receptor area far from their sources. coal emissions, aluminum production, home heating, cooking activities, motor vehicles, forest fires, coal-fired power plants and waste burning generate $P A H$ emission. Meanwhile, PAHs exchanging process in air, water and soil occurs due to dry deposition, wet deposition and evaporation of water and soil. PAHs exposure to human body have several pathways through inhalation, ingestion and skin contact. PAHs in airborne particles of less than $10 \mu \mathrm{m}\left(P M_{10}\right)$ can be inhaled, subsequently accumulated in the human respiratory system, and cause human health problems. Ambient air quality standards for PAHs toxic compounds have to be established to protect public health.
\end{abstract}

Keywords: benzo[a]pyrene, carcinogenic, deposition 


\section{PENDAHULUAN}

Polycyclic Aromatic Hydrocarbons (PAHs) merupakan kelompok senyawa Polycyclic Organic Matter (POM) yang diidentifikasi sebagai Toxic Air Contaminant. PAHs dihasilkan oleh pembakaran tidak sempurna batu bara, diesel, tar batubara, tembakau, letusan gunung berapi, knalpot kendaraan bermotor, dll (Prakash, 2019).PAHs terdistribusi luas di lingkungan, bersifat persisten dan toksik, serta mempunyai potensi bioakumulasi di lingkungan (Bi dkk, 2016).

PAHs mendapat perhatian dalam penelitian pencemaran udara karena senyawa ini bersifat karsinogenik atau mutagenik, terutama benzo[a]pyrene (EPA, 1999). United States Environmental Protection Agency (US EPA) mengidentifikasi 16 (enam belas)senyawa PAHs sebagai polutan PAHs utama yaitu naphthalene, anthracene, phenanthrene, fuoranthene, pyrene, benzo[a]anthracene, chrysene, benzo[b]fluoranthene, benzo[k]fluoranthene, perylene, benzo[a]pyrene, benzo[e]pyrene, benzo[g,h,i]perylene, indeno[1,2,3-cd]pyrene, dibenz[a, h]anthracene, dan coronene.

\section{SIFAT FISIK KIMIA DAN SUMBER PAH}

\subsection{Sifat Fisik Kimia Polycyclic Aromatic Hydrocarbons (PAHs)}

Sifat fisik kimia PAHs utama yaitu rumus molekul, berat molekul, titik didih $\left({ }^{0} \mathrm{C}\right)$, titik leleh $\left({ }^{\circ} \mathrm{C}\right)$, serta tekanan uap $(\mathrm{kPa})$ dijelaskan dalam Tabel $\mathbf{1}$.

Tabel 1. Struktur Kimia dan Sifat Fisik PAHs Utama

\begin{tabular}{|c|c|c|c|c|c|}
\hline Senyawa PAHs & $\begin{array}{l}\text { Rumus } \\
\text { Molekul }\end{array}$ & $\begin{array}{c}\text { Berat } \\
\text { Molekul }\end{array}$ & Titik Didih $^{\circ} \mathrm{C}$ & $\begin{array}{c}\text { Titik } \\
\text { Leleh }{ }^{\circ} \mathrm{C}\end{array}$ & $\begin{array}{c}\text { Tekanan Uap } \\
\text { kPa }\end{array}$ \\
\hline Naphthalene & $\mathrm{C}_{10} \mathrm{H}_{8}$ & 128,18 & 80,2 & 218 & $1,1 \times 10^{-2}$ \\
\hline Anthracene & $\mathrm{C}_{14} \mathrm{H}_{10}$ & 178,24 & $216-219$ & 340 & $36 \times 10^{-6}$ \\
\hline Phenanthrene & $\mathrm{C}_{14} \mathrm{H}_{10}$ & 178,24 & $96-101$ & $339-340$ & $2,3 \times 10^{-5}$ \\
\hline Fluoranthene & $\mathrm{C}_{16} \mathrm{H}_{10}$ & 202,26 & $107-111$ & $375-393$ & $6,5 \times 10^{-7}$ \\
\hline Pyrene & $\mathrm{C}_{16} \mathrm{H}_{10}$ & 202,26 & $150-156$ & $360-404$ & $3,1 \times 10^{-6}$ \\
\hline Benzo[a]anthracene & $\mathrm{C}_{18} \mathrm{H}_{12}$ & 228,30 & $157-167$ & 435 & $1,5 \times 10^{-8}$ \\
\hline Chrysene & $\mathrm{C}_{18} \mathrm{H}_{12}$ & 228,30 & $252-256$ & $441-448$ & $5,7 \times 10^{-10}$ \\
\hline Benzo[b]fluoranthene & $\mathrm{C}_{20} \mathrm{H}_{12}$ & 252,32 & $167-168$ & 481 & $6,7 \times 10^{-8}$ \\
\hline Benzo[k]fluoranthene & $\mathrm{C}_{29} \mathrm{H}_{12}$ & 252,32 & $198-217$ & $480-471$ & $2,1 \times 10^{-8}$ \\
\hline Perylene & $\mathrm{C}_{20} \mathrm{H}_{12}$ & 252,32 & $273-278$ & $500-503$ & $7,0 \times 10^{-10}$ \\
\hline Benzo[a]pyrene & $\mathrm{C}_{20} \mathrm{H}_{12}$ & 252,32 & $177-179$ & $493-496$ & $7,3 \times 10^{-10}$ \\
\hline Benzo[e]pyrene & $\mathrm{C}_{20} \mathrm{H}_{12}$ & 252,32 & $178-179$ & 493 & $7,4 \times 10^{-10}$ \\
\hline Benzo $[g, h, i]$ perylene & $\mathrm{C}_{22} \mathrm{H}_{12}$ & 276,34 & $275-278$ & 525 & $1,3 \times 10^{-11}$ \\
\hline Indeno $[1,2,3$-cd]pyrene & $\mathrm{C}_{22} \mathrm{H}_{12}$ & 276,34 & $162-163$ & - & $\operatorname{cax} 10^{-11}$ \\
\hline Dibenz $[a, h] a n t h r a c e n e$ & $\mathrm{C}_{22} \mathrm{H}_{14}$ & 278,35 & $266-270$ & 524 & $1,3 \times 10^{-11}$ \\
\hline Coronene & $\mathrm{C}_{10} \mathrm{H}_{8}$ & 300,36 & $438-440$ & 525 & $2,0 \times 10^{-13}$ \\
\hline
\end{tabular}

Sumber : EPA,1999; Gaga,2004

PAHs mempunyai kelarutan dan volatilitas rendah kecuali naphtalene, kelarutan PAHs dalam air semakin berkurang seiring meningkatnya berat molekul. Secara alami PAHs dengan bobot molekul rendah secara alami terdapat di atmosfer dalam konsentrasi yang cukup rendah, sedangkan PAHs dengan bobot molekul tinggi umumnya terbentuk karena proses pembakaran.Psikokimia dasar dan singkatan senyawa PAHs dijelaskan pada Tabel 2. 
Tabel 2. Psikokimia Dasar dan Singkatan Senyawa PAHs

\begin{tabular}{|c|c|c|c|c|}
\hline Senyawa PAHs & Singkatan & $\begin{array}{c}\text { Kelarutan } \\
\text { dalam air } \\
{\left[\mathrm{mgL}^{-1}\right]}\end{array}$ & $\begin{array}{c}\text { Koefisien } \\
\text { Partisi pada } \\
25^{\circ} \mathrm{C} \\
\end{array}$ & $\begin{array}{c}\text { Konstanta Hukum } \\
\text { Henry's }\left[\text { Pam }^{3}\right] \\
\text { pada } 25^{\circ} \mathrm{C}\end{array}$ \\
\hline Naphthalene & $\mathrm{NP}$ & 31 & 3,37 & 42,6 \\
\hline Phenanthrene & PHE & 1,1 & 4,46 & 4,3 \\
\hline Anthracene & ANT & 0,04 & 4,49 & 4,45 \\
\hline Fluoranthene & FLA & 0,2 & 8,9 & 1,96 \\
\hline Pyrene & PYR & 0,13 & 8,8 & 1,7 \\
\hline Benzo[a]anthracene & $\mathrm{BaA}$ & 0,011 & 5,8 & 1,22 \\
\hline Chrysene & $\mathrm{CHR}$ & 0,0019 & 5,73 & 0,53 \\
\hline Benzo[b]fluoranthene & $\mathrm{BbF}$ & 0,0015 & 5,78 & 0,05 \\
\hline Benzo[k]fluoranthene & $\mathrm{BkF}$ & 0,0008 & 6,5 & 0,04 \\
\hline Benzo[j]fluorantene & $\mathrm{BjF}$ & 0,0025 & 6,4 & - \\
\hline Benzo[a]pyrene & $\mathrm{BaP}$ & 0,0015 & 6,35 & 0,07 \\
\hline Benzo[e]pyrene & $\mathrm{BeP}$ & 0,007 & 6,44 & 0,02 \\
\hline Dibenzo[a, $h]$ antracene & DahA & 0,0005 & 6,5 & 0,0075 \\
\hline Benzo[g,h,i]perylene & BghiP & 0,00014 & 6,63 & 0,031 \\
\hline Indeno $[1,2,3-c-d] p y r e n e$ & IcdP & 0,00019 & 6,7 & 0,029 \\
\hline
\end{tabular}

Sumber : Tobiszweki dan Namiesnik, 2012

PAHs di atmosfer mengalami fotolisis atau oksidasi melalui reaksi dengan radikal $\mathrm{OH}$, ozon, nitrogen oksida atau pengoksidasi kuat lainnya (Marr dkk, 2006), beberapa PAHs mengalami reaksi oksidasi heterogen melalui media tetesan air (Raja dan Valsaraj, 2006). Waktu paruh ( half-lives) hasil reaksi fotolisis PAHs pada partikulat di atmosfer lebih rendah dibandingkan pada air atau pelarut organik (Niu dkk, 2007). Fase PAHs di atmosfer dijelaskan pada Tabel 3.

Tabel 3. Fase PAHs di Atmosfer

\begin{tabular}{|c|c|}
\hline Senyawa PAHs & Fasa \\
\hline Acenaphthene & Gas \\
\hline Acenaphthylene & Gas \\
\hline Anthracene & Partikel, gas \\
\hline Phenanthrene & Partikel, gas \\
\hline Pyrene & Partikel, gas \\
\hline Benzo[a]anthracene & Partikel \\
\hline Chrysene & Partikel \\
\hline Benzo[b]fluoranthene & Partikel \\
\hline Benzo[k]fluoranthene & Partikel \\
\hline Benzo[a]pyrene & Partikel \\
\hline Benzo[e]pyrene & Partikel \\
\hline Fluorine & Gas \\
\hline Dibenz[a,h]anthracene & Partikel \\
\hline Benzo[g,h,i]perylene & Partikel \\
\hline Indeno $[1,2,3-c, d]$ pyrene & Partikel \\
\hline
\end{tabular}




\subsection{Sumber Polycyclic Aromatic Hydrocarbons (PAHs)}

Sumber paling penting PAHs adalah emisi batu bara, produksi aluminium, pemanas domestik dan perumahan, kegiatan memasak, lalu lintas kendaraan bermotor, kebakaran hutan, pembangkit listrik berbahan bakar batubara dan pembakaran sampah. Konsentrasi tertinggi PAHs di atmosfer dapat ditemukan di lingkungan perkotaan karena meningkatnya lalu lintas kendaraan dan tidak adanya dispersi dari polutan di atmosfer.

Risiko terkait dengan paparan PAHs di udara tertinggi terjadi di kota-kota mengingat kepadatan penduduknya (Caricchia dkk, 1999 dalam Gaga, 2004). PAHs di udara perkotaan juga telah dikaitkan dengan emisi pembakaran kayu dari perumahan (Alberta, 2004), seperti dijelaskan pada Tabel 4.

Tabel 4. Sumber PAHs di Atmosfer

\begin{tabular}{ll}
\hline \multicolumn{1}{c}{ Sumber } & \multicolumn{1}{c}{ Senyawa PAHs } \\
\hline Pembakaran batu bara & Phenanthrene, fourantene, pyrene \\
\hline Memasak & Anthracene, pheanthrene, benzo(a)pyrene \\
\hline Insenerator air limbah & Pyrene, phenanthrene, flouranthene \\
\hline Pembakaran kayu & Benzo(a)pyrene, flouranthene \\
\hline Pembakaran bahan bakar minyak & Fluoranthene, pyrene \& CHR \\
\hline Mesin dengan bahan bakar bensin & Fluoranthene, pyrene, benzo[b]fluoranthene \\
\hline Mesin dengan bahan bakar solar & $\begin{array}{l}\text { Fluoranthene, pyrene, benzo[b]fluoranthene, } \\
\text { benzo[k]fluoranthene }\end{array}$ \\
\hline
\end{tabular}

Sumber : Rubailo dan Oberenko, 2008

Hasil analisis model reseptor membuktikan identifikasi 4 (empat) sumber kontribusi total PAHs pada PM10 di Kota Zaragoza Spanyo yaitu pembakaran batubara, emisi kendaraan, emisi bensin dan emisi peralatan menulis (Calllen dkk, 2012).

\section{TOKSISITAS DAN KARSINOGENITAS POL YCYCLIC AROMATIC HYDROCARBONS(PAHS)}

PAHs bersifat karsinogenik sebagian besar terikat dengan partikulat (Bi dkk, 2003; Ravindra dkk, 2008). Konsentrasi PAHs di atmosfer sangat tergantung pada ukuran partikulat udara (Particulate Matter,PM) (Lodovici dkk, 2003). Partikel-partikel dengan diameter kurang dari $10 \mu \mathrm{m}\left(\mathrm{PM}_{10}\right)$ dapat terdeposit dan terakumulasi dalam sistem pernapasan dan dapat menyebabkan ancaman signifikan terhadap kesehatan manusia (Wiriya, 2013).

Partikulat polutan udara terutama partikel halus dengan diameter aerodinamis yaitu kurang dari 2,5 $\mathrm{m}\left(\mathrm{PM}_{2.5}\right)$ berkaitan dengan peningkatan morbiditas dan mortalitas, serta berbagai efek merugikan kesehatan seperti penyakit pernapasan dan kardiovaskular. Partikel $\mathrm{PM}_{2.5}$ dengan senyawa toksik PAHs memiliki hubungan lebih lanjut yaitu meningkatkan efek kesehatan.

Paparan PAHs dapat terjadi melalui tiga rute yaitu pernafasan, mulut dan penyerapan kulit. Dosis potensial karsinogenik PAHs melalui pernafasan yaitu antara 0,02 - 3 $\mu \mathrm{g} / \mathrm{hari}$ dengan nilai tengah 0,016 $\mu \mathrm{g} / \mathrm{hari}$ dimana hampir 20 kali kurang dari perhitungan dosis pada makanan dan sekitar 25 kali lebih dari dosis potensial air yang terminum, seperti dijelaskan dalam Tabel 5. 
Tabel 5. Dosis Potensial Karsinogenik PAHs

\begin{tabular}{lcccc}
\hline \multirow{2}{*}{ Sumber PAHs } & \multicolumn{3}{c}{ Dosis potensial karsinogenik PAHs } \\
\cline { 2 - 5 } & \multicolumn{2}{c}{ Bukan perokok } & \multicolumn{3}{c}{ Perokok } \\
\cline { 2 - 5 } & $\mu \mathrm{g} / \mathrm{hari}$ & $\%$ dari total & $\mu \mathrm{g} /$ hari & $\%$ dari total \\
\hline Makanan & 3 & 93,0 & 3 & 44,6 \\
\hline Udara & 0,16 & 4,9 & 0,16 & 2,4 \\
\hline Air & 0,006 & 0,2 & 0,006 & $<0,01$ \\
\hline Tanah (kecelakaan terhirup) & 0,06 & 1,9 & 0,06 & 1 \\
\hline Asap rokok & - & - & $3,5 *$ & 52 \\
\hline Total & 3,22 & 100 & 6,7 & 100 \\
\hline
\end{tabular}

Sumber : Menzie dkk,1992

Benzo[a]pyrene digunakan sebagai indikator meskipun kehadirannya hanya $3-20 \%$ dari total senyawa PAHs secara keseluruhan, Hal ini disebabkan sifat karsinogenik PAHs sangat besar yaitu $30-100 \%$. Penetapan benzo[a]pyrene sebagai indikator juga berdasarkan karakteristik dan spektrum fluoresence khusus pada wilayah spektral tampak (Menzie dkk,1992).

\section{PATHWAY POL YCYCLIC AROMATIC HYDROCARBONS(PAHS) DI LINGKUNGAN}

Deposisi kering, deposisi basah, akumulasi dan degradasi merupakan proses penghilangan PAHs dari lingkungan (Abdel-Shafy dan Mansour, 2016; Zong dan Zou, 2013). Total deposisi atmosfer PAHs dilakukan untuk mengukur deposisi kering dan deposisi basah deposisi. Hasil deposisi kering dari impaksi langsung di darat dan air dari udara dari gas dan partikulat PAHs,seperti dijelaskan pada Gambar 1.

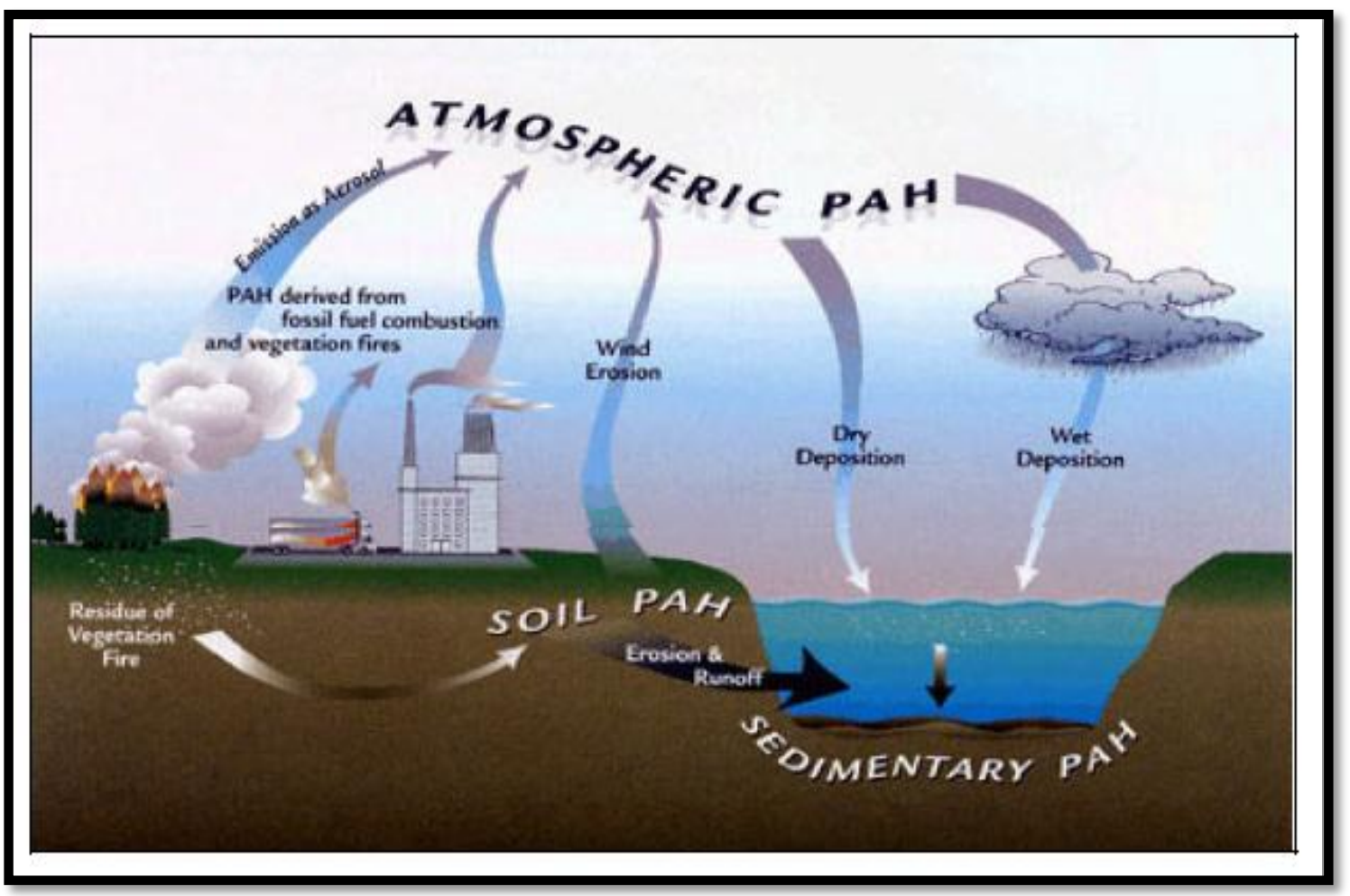

Gambar 1. Pathway PAHs di Lingkungan (Sumber:http://www.inchem.org/documents/ehc/ehc/ehc202.htm) 
PAHs di udara relatif berumur pendek yaitu sampai sepuluh jam (Mackay dkk, 1995). Dengan demikian PAHs dalam udara kering tidak bepergian sangat jauh dari sumber emisi hanya untuk jarak kurang dari sepuluh kilometer. Deposisi basah terbawa ke permukaan dengan pengendapan hidrometeors (hujan dan serpih salju). Waktu tinggal PAHs dalam fase cair dari sepuluh sampai hingga ratusan jam (Mackay dkk, 1995). Tetesan awan mengakumulasi gas dan partikulat PAHs pada saat mereka melakukan perjalanan jarak jauh.

Deposisi basah PAHs mungkin berasal dari daerah perkotaan atau sumber-sumber industri ratusan ribu kilometer jauhnya. Pada daerah perkotaanatau daerah industri deposisi kering mendominasi, sedangkan di daerah terpencil deposisi basah bersifat lebih dominan (Golomb dkk, 1997). Air hujan dapat merupakan sumber utama PAHs utama di suatu wilayah karena bentuk gas dan partikel PAHs dapat dengan mudah terdeposisi basah melalui hujan (Poster dan Baker,1996).

Deposisi PAHs dengan fase partikulat yang lebih besar dari $3-5 \mathrm{~nm}$ dan atau fase gas PAHs akan teruapkan kembali ketika pertama kali terdeposisi sangat dipengaruhi oleh kondisi meteorologi dan polutan udara ambient (Bin dkk,2007). Parameter meteorologi mempunyai peran penting pada deposisi atmosfer senyawa PAHs terutama temperatur atmosfer sangat mempengaruhi penghilangan senyawa PAHs dengan berat molekul rendah. Hal inimenyebabkan risiko paparan senyawa PAHs maksimum pada seluruh matriks lingkungan terjadi pada saat musim kemarau (Subhankar dan Ambade, 2016).

Partisi senyawa PAHs dalam lingkungan dijelaskan pada Tabel 6.

Tabel 6. Partisi PAHs dalam Lingkungan

\begin{tabular}{lcc}
\hline \multirow{2}{*}{ Lingkungan } & \multicolumn{2}{c}{ Persen (\%) dari Total } \\
\cline { 2 - 3 } & $\Sigma \mathrm{PAH}$ & Benzo[a]pyrene \\
\hline Tanah & 94,4 & 92,9 \\
\hline Sedimen perairan alami & 5,4 & 7,1 \\
\hline Air & $<0,01$ & $<0,01$ \\
\hline Udara & 0,1 & $<0,01$ \\
\hline Tanaman & 0,1 & $<0,01$ \\
\hline Biota & $<0,01$ & $<0,01$
\end{tabular}

Sumber : Wild dan Jones, 1995

Senyawa PAHs cenderung berkumpul dalam sedimen perairan yang dekat dengan perkotaan, senyawa tersebut mudah mengendap di dasar perairan dan sangat beracun bagi organisme perairan. PAHs yang terlarut dalam air pada kadar antara 0,1 - $5 \mathrm{ppm}$ sudah dapat menyebabkan keracunan terhadap semua larva biota perairan (Munawir, 2007). Senyawa PAHs akan terakumulasi menjadi kadar yang tinggi dalam tubuh hewan tingkat rendah dalam perairan karena senyawa ini sukar dicerna dalam tubuhnya (Uthe,1991).

Keberadaan PAHs di tanah dapat mengkontaminasi air tanah di wilayah sekitarnya. Konsentrasi PAHs dalam tanaman dan binatang yang tinggal di atas tanah atau dalam air dapat lebih tinggi dibandingkan konsentrasi PAHs dalam tanah atau air tersebut. PAHs dapat terdegradasi di udara dalam waktu lama karena bereaksi dengan sinar matahari dan reaksi kimia, secara umum dalam periode hari sampai minggu. Degradasi dalam tanah dan air dapat terjadi beberapa minggu sampai berbulan bulan oleh aktivitas mikroorganisme (ATSDR, 1990). 


\section{DAMPAK POL YCYCLIC AROMATIC HYDROCARBONS(PAHS)}

Penilaian paparan PAHs lingkungan dapat dilakukan melalui pemantauan lingkungan dimana konsentrasi PAHs ditentukan dalam sampel lingkungan (udara, makanan, air, tanah, dll), sedangkan pada manusia melalui biomonitoring internal kadar PAHs dalam tubuh (misalnya: PAHs-hidroksi urin atau OH-PAHs)sebagai indikator penilaian keseluruhan eksposur PAHs. PAHs dalam udara perkotaan disebabkan paparan yang terus menerus dan populasi yang mempunyai risiko. Udara perkotaan sangat kompleks dan mempunyai sistem yang dinamis berbagai spesies kimia dalam bentuk gas dan partikulat (Thai dkk, 2015).

Senyawa PAHs dapat menjangkau tubuh manusia melalui bentuk paparan pernafasan langsung akibat udara tercemar, pernafasan langsung dari tembakau, pencernaan dari makanan dan yang terkontaminasi serta kontak melalui kulit. Sumber utama dari paparan PAHs kepada masyarakat adalah udara ambien yang tercemar, asap dari perapian terbuka dan memasak, asap tembakau, makanan dan air minum yang terkontaminasi dan penggunaan produk yang terkontaminasi PAHs (WHO, 2000).

PAHs dapat ditemukan di udara dalam ruangan sebagai hasilnya pemanasan perumahan dan asap tembakau lingkungan di rata-rata konsentrasi $1-100 \mathrm{ng} / \mathrm{m}^{3}$ dengan maksimum $2.300 \mathrm{ng} / \mathrm{m}^{3}$. Asupan PAHs secara individu dari makanan telah diperkirakan 0,10-10 mg/hari per orang. Total asupan harian benzo[a]pyrenedari air minum diperkirakan 0,0002 mg/orang. Sereal dan produk sereal adalah kontributor utama asupan PAHs dari makanan, karena merupakan komponen utama dari produk diet secara keseluruhan (Alberta, 2004).

Sejumlah PAHs dapat menyebabkan tumor kepada hewan percobaan di laboratorium jika terpapar PAHs pada makanan, melalui pernafasan udara yang tekontaminasi dan jika diaplikasikan pada kulit hewan tersebut. Tikus hamil yang memakan dosis benzo[a]pyreneakan mengalami masalah reproduksi. Keturunan dari tikus yang hamil tersebut menunjukan cacat lahir dan penurunan berat badan. Efek lain antara lainkerusakan terhadap kulit, cairan tubuh dan sistem kekebalan tubuh, meskipun dampak terhadap manusia belum tampak (US EPA,2008).

\section{MITIGASI POL YCYCLIC AROMATIC HYDROCARBONS (PAHS)}

Section 112 dari Clean Air Act Amandemen 1990 membentuk sebuah program nasional yang baru untuk mengurangi secara signifikan emisi pencemar udara toksik termasuk senyawa PAHs untuk melindungi kesehatan manusia. Program ini terdiri dari2 (dua) tahap yaitu standar teknologi yang dibutuhkan berdasarkan Maximum Achievable Control Technology (MACT) untuk kategori sumber spesifik dan perhitungan risiko serta penghilangan yang dibutuhkan sampai batas keselamatan untuk melindungi kesehatan masyarakat (Patrick dkk,1994).

Pengurangan emisi dari industri logam dan industri besi yang menghasilkan emisi benzo[a]pyrenedi Jerman dilakukan dengan menggunakan teknologi tekanan pada ruang pembakaran SOPRECO (Single Oven Pressure Control System) menggunakan 50 buah oven sehingga memenuhi baku mutu benzo[a]pyrene $1 \mathrm{mg} / \mathrm{m}^{3}$ (Hein dan Kaiser, 2012). Catalytic converter untuk mesin diesel dapat digunakan untuk mengurangi emisi total PAHs dari kendaraan meskipun pengurangannya tidak sebesar mesin bensin (Hall dkk,1998). Pada mesin diesel yang menggunakan mesin turbo dan sistem pendinginan untuk mengurangi emisi partikulat dan catalytic converter sangat efisien pada pengurangan emisi partikel organik. Pemakaian catalytic converter pada mesin dengan bahan bakar bensin dapat emisi 
PAHs lebih dari 90\% (Chen dkk,2001). Pembakaran gas dan oli modern digunakan untuk sistem sirkulasi pemanas dan sistem pemanas air relatif mempunyai emisi PAHs yang rendah. Begitupun sistem pembakaran bahan padat (kayu, batu bara, dan gambut) yang secara otomatis dikontrol dan diisi adalah lebih efisien pemanasannya dan mempunyai emisi yang lebih rendah dibandingkan dengan pengisiannya dengan manual (Ravindra dkk,2008). Pemanasan ruangan dapat menggunakan "heating" dengan menggunakan energi listrik sehingga tidak lagi mengeluarkan emisi pembakaran.

Organisasi Kesehatan Dunia (WHO, 2000) merekomendasikan standar nilai udara ambien untuk benzo[a]pyreneadalah $0,0012 \mu \mathrm{g} / \mathrm{m}^{3}$ untuk masyarakat umum menggunakan unit faktor risiko inhalasi $8,7(10-5)$ per $\mathrm{ng} / \mathrm{m}^{3}$ dan dihubungkan dengan kelebihan tingkat risiko seumur hidup untuk 1 dari 100.000 orang. Kementerian Lingkungan Hidup (KLH) Ontario (Ontario Ministry of the Environment/ MOE) mengadopsi Kriteria Standar Kualitas Udara Ambien (Ambient Air Quality Criterion/ AAQC) yaitu $0,0011 \mu \mathrm{g} / \mathrm{m}^{3}$ untuk pengukuran 24 jam.

MOE menggunakan beberapa titik maksimum standar paparan yaitu $0,0033 \mathrm{~g} / \mathrm{m}^{3}$ dari sumber tunggal untuk waktu rata-rata 30 menit dan $0,00022 \mu \mathrm{g} / \mathrm{m}^{3}$ dari sumber tunggal untuk waktu rata-rata tahunan dan $0,0003 \mu \mathrm{g} / \mathrm{m}^{3}$ dari semua sumber untuk waktu rata-rata tahunan (Alberta,2004).Standar kualitas udara untuk benzo[a]pyrenedi Inggris adalah 0,25 $\mathrm{ng} / \mathrm{m}^{3}$, sedangkan di Negara Eropa adalah $1,0 \mathrm{ng} / \mathrm{m}^{3}$ (EPA QSDirective 2008, Callen 2012). Peraturan batas dosis paparan per hari benzo[a]pyrene di China adalah $10 \mathrm{ng} / \mathrm{m}^{3}$ untuk peraturan batas dosis paparan per hari (EPA, 1998; Ma,2010).

Hasil perhitungan nilai ILCR (Incremental Lifetime Cancer Risk) PAHs atmosferik melalui inhalasi $\mathrm{PM}_{2,5}$ pada kelompok populasi berbeda yaitu kurang dari $10^{-6}$ untuk pria dewasa, wanita dewasa, anak-anak laki-laki, dan anak-anak perempuan. Hasil ini menunjukkan bahwa tidak ada risiko kanker untuk populasi yang tinggal di 5 (lima) kota di Provinsi Zhejiang China, meskipun konsentrasi PAHs lebih tinggi dari Chinese National Ambient Air Quality Standard (NAAQS) (Mo dkk, 2019).

\section{KESIMPULAN}

Polycyclic Aromatic Hydrocarbons (PAHs) mendapat perhatian dalam penelitian pencemaran udara karena senyawa ini bersifat karsinogenik atau mutagenik, terutama Benzo[a]pyrene.Konsentrasi PAHs di atmosfer sangat tergantung pada ukuran partikulat udara dimana partikel-partikel dengan diameter kurang dari $10 \mu \mathrm{m}\left(\mathrm{PM}_{10}\right)$ dapat deposit dan terakumulasi dalam sistem pernapasan dan dapat menyebabkan ancaman yang signifikan terhadap kesehatan manusia. Deposisi kering dan basah partikel dan gas PAHs merupakan jalur utama penyebaran PAHs di lingkungan daratan, air permukaan, danau dan sedimen.

Senyawa PAHs dapat menjangkau tubuh manusia melalui bentuk paparan pernafasan langsung akibat udara tercemar, pernafasan langsung dari tembakau, pencernaan dari makanan dan air yang terkontaminasi PAHs, serta kontak langsung melalui kulit. Pengurangan emisi dari industri logam dan besi yang menghasilkan emisi benzo[a]pyrene dapat dilakukan dengan mengganti teknologi konvensional dengan SOPRECO (Single Oven Pressure Control System), sehingga dapat memenuhi baku mutu benzo[a]pyrene yaitu1 $\mathrm{mg} / \mathrm{m}^{3}$. Catalytic converter untuk mesin diesel dapat digunakan untuk mengurangi emisi total PAHs dari kendaraan, sertapenggunaan tungku pembakaran otomatis dapat digunakan untuk mengurangi emisi total PAHs dari pembakaran kayu. Baku mutu udara ambien untuk senyawa PAHs perlu ditetapkan pemerintahuntuk melindungi kesehatan masyarakatsuatu negara. 


\section{DAFTAR RUJUKAN}

http://www.inchem.org/documents/ehc/ehc/ehc202.htm

Abdel-Shafy H.I,dan Mansour M.S.M. (2016). A review on polycyclic aromatic hydrocarbons: Source, environmental impact, effect on human health and remediation. Egyptian Journal of Petroleum, 25, 107-123.

Agency for Toxic Substances and Disease Registry (ATSDR). (1990). Public Health Statement, Polycyclic Aromatic Hydrocarbons, December 1990. U.S. Public Health Service, U.S. Department of Health and Human Services, Atlanta, GA. December 1990.

Agency for Toxic Substances and Disease Registry (ATSDR). (1995). Toxicological Profile for Polycyclic Aromatic Hydrocarbons, August 1995. U.S. Public Health Service, U.S. Department of Health and Human Services, Atlanta, GA, August 1995

Alberta Environment. (2004). Review of approaches for setting an objective for mixtures in ambient air using polycyclic aromatic hydrocarbons (PAHs) as an example: Benzo[a]pyrene.

Bi, X., Sheng, G., Peng, P., Chen, Y., Zhang, Z., Fu, J. (2003). Distribution of particulate and vapor-phase n-alkanes and polycyclic aromatic hydrocarbons in urban atmosphere of Guangzhou, China. Atmos. Environ. 37, 289-298.

Bi, X., Luo, W., Gaoa, J., Xua, L., Guo J., Zhang Q., Romesh, K.Y.,Giesy, J.P., Shichang Kang, S., Boer, J. (2016).Polycyclic aromatic hydrocarbons in soils from the CentralHimalayaregion: Distribution, sources, and risks to humans and wildlifeScience of the Total Environment 556, 12-22

Bidleman, T. F.(1988). Atmospheric Processes. Environ. Sci. Technol, 22, 361-367.

Bin L.L., Yan L., Ming L.J., Ning T., Kazuichi H., Tsunaeki M. (2007). Development of analytical methods for polycyclic aromatic hydrocarbons (PAHs) in air particulates : A review. Journal of Environmental Sciences 19, 1-11.

Callén, M.S.,López, J.M., Iturmendi, A., Mastral, A.M. (2012). Nature and sources of particle associated polycyclic aromatic hydrocarbons (PAH)in the atmospheric environment of an urban area. Environmental Pollution, 1-9.

Chen S,J., Jian W.J., Huang Y.C. (2001). PAHs and aerosol carbon in the exhaust of a gasoline powered engine. Aerosol and Air Quality Research Vol.1 No. 1., p $57-67$

EPA. (1998). Locating and Estimating Air Emission from Sources of Polysiclic Aromatic Matter. United States Environmental Agency 454/R-98-014.

Environmental Protection Agency (EPA). (1999). Determination of polycyclic aromatic hydrocarbons (PAHs) in ambientair using gas chromatography/mass spectrometry (GC/MS). Second Edition Compendium Method TO-13A.

Environmental Protection Agency (EPA). (2008).Ambient Air Quality and Cleaner Air for Europe (CAFE) Directive (2008/50/EC). https://www.epa.ie/air/quality/standards/.

Gaga E.O. (2004). Investigation of Polycyclic Aromatic Hydrocarbon (PAH) Deposition in Ankara. The Middle East Technical University.

Giri S.K., Kumar A., Kumar A., Gulati S. (2016). Effects of Polycyclic Aromatic Hydrocarbons on Environment Health. https://www.researchgate.net/publication/301888451.

Golomb, D., Ryan D., Underhill, J., Wade, T., dan S. Zemba, S. (1997). Atmospheric deposition of toxics onto Massachusetts Bay II Polycyclic Aromatic Hydrocarbons. Armosphenc Enutronmenr 31 (9), 1361-1368.

Hall, D.E., Doel, R., Jorgensen, R., King, D.J., N. Mann, N., Scorlett, P. (1998). Polycyclic aromatic hydrocarbons in automotive exhaust emissions and fuel. CONCAWE.

Hanedar A., Alp K., Kaynak B., Baek J., Avsar E., Odman M.T. (2011). Concentrations and sources of PAHs at three stations in Istanbul, Turkey. Atmospheric Research 99, 391-399 
Harner, T., Bidleman, T.F., (1998). Octanol-air partition coefficientfor describing particle/gas partitioning of aromaticcompounds in urban air. Environmental Science and Technology32, 1494-1502.

Hein, M., dan Kaiser, M. (2012). Environmental Control and Emission Reduction for Coking Plants. Air Pollution - A Comprehensive.Air Pollution: A Comprehensive Perspective.

Liu F., Xu Y., Liu J., Liu D., Li J., Zhang G., Li X., Zou S., Lai S. (2013). Atmospheric deposition of polycyclic aromatic hydrocarbons (PAHs) to a coastal site of Hong Kong, South China. Journal Atmospheric Environment 69 : p 265-272.

Lodovici, M., Venturini, M., Marini, E., Grechi, D., Dolara, P. (2003). Polycyclic aromatic hydrocarbons air levels in Florence, Italy, and their correlation with other air pollutants. Chemosphere 50, 377-382.

Ma, W.L., Li, Y.-F., Qi, H., Sun, D.Z., Liu, L.Y., dan Wang, D.-G. (2010). Seasonal variations of sources of polycyclic aromatic hydrocarbons (PAHs) to a northeastern urban city, China. Chemosphere, 79(4), 441-447.

Maliszewska B., Kordybach. (1999). Sources, Concentations, fate and effects of Polycyclic Aromatic Hydrocarbons (PAHs) in The Environment Part A : PAHs in Air. Polish of Journal of Environmental Studies Volume 8 No. 3, p 131-136.

Mackay, D., Wan-Ying Shiu and K.C. Ma. 1995. Illustrated Handbook of Physical-Chemical Properties and Environmental Fate of Organic Chemicals. Vol. 4. Lewis Publishers, Boca Raton, FL.

Marr, L.C., Dzepina, K., Jimenez, J.L., Reisen, F., Bethel, H.L., Arey, J., Gaffney, J.S.,Marley, N.A., Molina, L.T., Molina, M.J., 2006. Sources and transformations ofparticle-bound polycyclic aromatic hydrocarbons in Mexico City. AtmosphericChemistry and Physics 6, 1733-1745

Munawir K. (2007). Kadar Polisiklik Aromatik Hidrokarbon (PAH) dalam air di Teluk Klabat. Oseanologi dan Limnologi di Indonesia Volume 33 (3).

Menzie C.A., Potocki B.B., Santodonato J. Exposure to carcinogenic PAHs in the environment, Environm. Sci. Technol. 26, 1278, 1992.

Mo, Z., Wang, Z., Mao, G., Pan, X., Wu, L., Xu, P., Chen, S., Wang, A., Zhang, Y., Luo, J., Ye, X., Wang, X.,Chen, Z., danLou, X. (2019). Characterization and healthrisk assessment of PM2.5-boundpolycyclic aromatic hydrocarbons in5 urban cities of Zhejiang Province,China. Scientific Reports9, Article number: 7296.

Niu, J., Sun, P., Schramm, K.-W., 2007. Photolysis of polycyclic aromatic hydrocarbonsassociated with fly ash particles under simulated sunlight irradiation.Journal of Photochemistry and Photobiology 186, 93-98.

Pitts B.J.F., Pitts J.JN. (1986). Atmospheric Cemistry Fundamentals and Experimental Techniques. A Wiley-Interscience Publication John Wiley \& Sons.

Prakash B.O. (2019). Persistent organic compounds in the environment their impact on human health: A review. GSC Biological and Pharmaceutical Sciences, 08(02), 081-088.

Raja, S., Valsaraj, K.T., 2006. On the reactive uptake of gaseous PAH molecules bymicronsized atmospheric water droplet. Atmospheric Research 81, 277-292.

Ravindra K., Sokhi R., Grieken R.V. (2008). Atmospheric olysiclic Aromatic Hydrocarbons : Source Attribution, Emission Factors and Regulation. Atmospheric Environment.

Rubailo, A.I., Oberenko, A.V. (2008). Polycyclic Aromatic Hydrocarbons as Priority Pollutants. Journal of Siberian Federal University. Chemistry, 4, 344-354

Seinfeld, John H, pandis S.N. (1998). Atmospheric Chemistry and Physics from Air Pollution to Climate Change, John Wiley and Son, Inc., New York.

Shubhankar B., Ambade B. (2016). A review on deposition of Polycyclic Aromatic Hydrocarbons in different environmental matrix and study its toxicity and carcinogenic effect. Asian Journal of Chemistry, 28 (11), 2341 - 234. 
Thai, P.K., Li, Z., Andreas Sjödin, A., Fox,A., Diep, N.B., Binh,T.T., dan Mueller, J.F. (2015). Biomonitoring of polycyclic aromatic hydrocarbons exposure in small groups of residents in Brisbane, Australia and Hanoi, Vietnam, and those travelling between the two cities. Chemosphere, 139, 358-364.

Tucker, S.A., Griffin, J.M., dan Acree, W.E.Jr. (1994). Selective Fluorescence Quenching to Discriminate Between Alternant and Non alternant Polycyclic Aromatic Hydrocarbons: Acephenanthrylene Derivatives as Except ions to the Nitromethane Quenching Rule. Analyst 11 (90), 2129-2133.

Tobiszewski M., Namiesnik J. (2012). Review : PAH diagnostic ratios for the identification of pollution emission sources. Environmental Pollution 162, 110-119.

United States Environmental Protection Agency. (2008). Polycyclic Aromatic Hydrocarbons (PAHs).

Uthe, J.F. (1991). Polycyclic aromatic hydrocarbon in the environment. Marine Chemistry Division, Departement of Fisher and Ocenas. Halifax.Canadian chemical news : 25-27.

Wild S.R., Jones K.C. (1995). Polynuclear aromatic hydrocarbons in the United Kingdom environment : a preliminary source inventory and budget. Environment Pllution 88, 91.

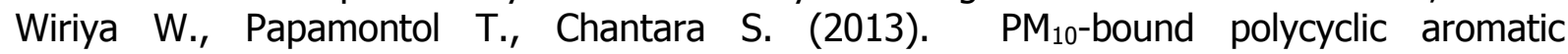
hydrocarbons in Chiang Mai (Thailand): Seasonal variations, source identification, health risk assessment and their relationship to air-mass movement. Atmospheric Research 124,109-122.

World Health Organization, (2000). WHO Guidelines for Indoor Air Quality: Selected Pollutants.

Zhong Y., dan Zhu L. (2013). Distribution, input pathway and soil-air exchange of polycyclic aromatic hydrocarbons in Banshan Industry Park, China. Science of the Total Environment, 444, 177-182. 